ARTICLE HISTORY: Received: May 4, 2021 Accepted: June 25, 2021 Published: July 3, 2021

УДК 504.054: 504.064.36:574

ОЦЕНКА ЗАГРЯЗНЕННОСТИ ЛЕДНИКОВЫХ ВОД РЕК ЦЕНТРАЛЬНОГО КАВКАЗА ЗА ПЕРИОД 2017-2018 ГОДЫ

\author{
Жинжакова Лилия Зуберовна ${ }^{1}$ \\ Чередник Елена Александровна \\ 1 стариий научный сотрудник \\ ФГБУ «Высокогорный геофизический институт» \\ Нальчик \\ 2 научный сотрудник \\ ФГБУ «Высокогорный геофизический институт» \\ Нальчик
}

\title{
ASSESSMENT OF POLLUTION OF GLACIAL WATERS OF THE RIVERS OF THE CENTRAL CAUCASUS FOR THE PERIOD 2017-2018
}

\author{
Zhinzhakova Liliya Zuberovna ${ }^{1}$ \\ Cherednik Elena Alexandrovna ${ }^{2}$ \\ 1 Senior staff scientist \\ FGBU «High-Mountain Geophysical Institute» \\ Nalchik \\ 2 Staff scientist \\ FGBU «High-Mountain Geophysical Institute» \\ Nalchik
}

Аннотация. Проведена оценка химического состава и качества ледниковых вод за период 2017-2018 годы по предельно допустимым концентрациям. Приводятся результаты исследования содержания микроэлемента Mn и минеральных соединений азота в водах ледниковых рек. По наблюдениям в этот период выявлены особенности вод исследуемых рек и их отличие по уровню загрязнения. Дана экологическая оценка загрязненности водных объектов по классификации качества поверхностных вод суши. Данные представлены в таблицах.

Abstract. The assessment of the chemical composition and quality of glacial waters for the period 2017-2018 was carried out according to the maximum permissible concentrations. The results of the study of the content of the trace element $\mathrm{Mn}$ and mineral nitrogen compounds in the waters of glacial rivers are presented. According to observations during this period, the features of the waters of the studied rivers and their difference in the level of pollution were revealed. An ecological assessment of the pollution of water bodies is given according to the classification of the quality of surface waters of the land. The data are presented in tables.

Ключевые слова. Реки, концентрация, марганец, нитраты, нитриты, аммоний, исследование.

Keywords. Rivers, concentration, manganese, nitrates, nitrites, ammonium, research.

\section{Введение}

В настоящее время изменение климата на Центральном Кавказе оказывает влияние на гидрологический режим рек [1]. Изучение состава речных вод и выявление уровней загрязнения токсичными и вредными ингредиентами в меняющихся условиях является важной задачей. В условиях глобального изменения климата происходит смещение сезонов «зима-лето-осень». Сезонные температурные значения изменяются с высотой водосбора [2]. За счет резких колебаний температуры происходят изменения в частоте и количестве выпадающих осадков, усиливая таяние ледников, формирующих основные водные артерии республики, оказывающие влияние на общий сток рек.

Реки республики, берущие начало в высокогорной зоне из-под ледников, являются важным «сырьем» для поддержания экологического равновесия и питания рек равнинной зоны Центрального Кавказа. Запасы чистой воды рек Центрального Кавказа являются надежным капиталом в экономике региона и страны. Необходимость наблюдений за составом и качеством речных вод связана со значением их для использования в рыболовстве, туризме, поливе сельскохозяйственных угодий, обеспечения населения питьевой водой и использования в промышленном производстве. Значение воды в природе велико для всего живого и является главным источником энергии. Исследование содержания вредных веществ в водных объектах, в том числе и опасных 
соединений азота - важной составляющей, является одной из задач третьего тысячелетия, решению которой способствует изучение и оценка качества ледниковых рек.

Последнее время в республике отмечаются сильные паводки, наводнения, сход лавин, наблюдается сброс недостаточно очищенных стоков и загрязненных неочищенных сточных вод. Наибольший сброс недостаточно очищенных сточных вод осуществляется предприятиями в реки Баксан, Малка, Чегем, Черек, Ардон, Терек. Резкое снижение качества воды в реках республики также обусловлено деятельностью спиртовых и крахмальных предприятий республики, изношенностью очистных сооружений, загрязнением русел и пойм рек бытовыми отходами, а также отходами предприятий. Все перечисленное может привести к разнообразным экологическим последствиям, связанным с эрозийными аккумулятивными процессами, влияющие на изменение химического состава и ухудшение качества речных вод, широко используемые населением в различных целях, а в летний период являются зоной отдыха вдоль берегов рек. Своевременное предупреждение, сохранение водных артерий и наблюдение за, возможно, возникающими экологическими проблемами является одной из проблем третьего тысячелетия, когда вода становится одним из ценных и дорогих продуктов для жизни человека и всего живого. На основании наблюдений за содержанием соединений азота в речных водах Центрального Кавказа установлен состав и уровень загрязнения основных рек.

Целью настоящей работы являлась оценка загрязненности речных вод неорганическими соединениями азота.

\section{Методы и материалы}

Анализ содержания загрязняющих веществ проводится в Высокогорном геофизическом институте в аккредитованной лаборатории более 15 лет [3]. Результаты в ранее опубликованных работах [4-9] отражают уровни загрязнения речных вод, но в связи с изменением климата вопрос остается актуальным. Отбор проб воды проводили в зимнюю межень и летний паводок по руководящему документу для поверхностных вод суши [10]. Верхний створ для каждой реки располагался в предгорно-низкогорной зоне, а замыкающий в равнинной части республики. Содержание $\mathrm{NO}_{2}{ }^{-}, \mathrm{NO}_{3}{ }^{-}$и $\mathrm{NH}_{4}{ }^{+}$в водах рек определяли методами химического анализа [11-13].

Прослежено изменение уровня загрязнения и качества вод на содержание Mn по методике [14]. Марганец относится к эссенциальному элементу, необходимому для жизнедеятельности растительных и живых организмов. Кларк марганца в земной коре высокий и варьирует в пределах 800-1000 мг/кг [15]. Предельно допустимая концентрация металла в поверхностных водах составляет 10 мкг/дм ${ }^{3}$ [16].

Дана оценка загрязненности речных вод по экологическим классам, при этом учитывались превышение уровня концентрации примеси над уровнем ПДК и экологические классы качества поверхностных вод суши [1719].

Анализ показал, что реки загрязнены нитрит- и аммонийными ионами, и концентрации увеличиваются к замыкающим створам, что, скорее всего, связано с антропогенным влиянием дополнительного количества примесей от населенных пунктов, через которые протекают эти реки. Источником поступления соединений азота являются смывы бытовых свалок и фермерских хозяйств, промышленные стоки. Повышенное содержание солей тяжелых металлов в водных экосистемах может быть обусловлено как загрязнением среды, так и геохимическими особенностями региона. В основное русло рек поступают грунтовые и подземные воды, обогащенные микроэлементами, в том числе воды многочисленных минеральных источников, находящихся в бассейнах представленных водотоков. На основе аналитических данных о содержании того или иного токсичного элемента в воде можно судить об опасности концентрации для живых организмов [20].

\section{Обсуждение результатов}

Значения концентраций неорганических соединений азота в водах рек с ледниковым питанием в период зимней межени (I) и летнего паводка (II), которые варьировали в широком диапазоне, представлены в табл.1.

Таблица 1

Концентрации примесей в водах ледниковых рек Центрального Кавказа, 2017-2018 годы [3,4]

\begin{tabular}{|c|c|c|c|c|c|c|c|c|c|}
\hline \multirow[t]{2}{*}{ Река } & \multirow{2}{*}{$\begin{array}{c}\text { Год } \\
\text { отбора }\end{array}$} & \multicolumn{2}{|c|}{$\begin{array}{l}\text { Mn, } \\
\text { Мкг/Дм }\end{array}$} & \multicolumn{2}{|c|}{$\begin{array}{l}\mathrm{NO}_{2}^{-}, \\
\mathrm{M \Gamma} / \mathrm{дM}^{3}\end{array}$} & \multicolumn{2}{|c|}{$\begin{array}{l}\mathrm{NO}_{3}^{-}, \\
\mathrm{M \Gamma} / \text { дм }^{3}\end{array}$} & \multicolumn{2}{|c|}{$\begin{array}{l}\mathbf{N H}_{4}^{+}, \\
\mathrm{M \Gamma} / \text { дм }^{3}\end{array}$} \\
\hline & & I & II & I & II & $\begin{array}{l}I \\
\end{array}$ & II & I & II \\
\hline \multirow[t]{4}{*}{ Малка } & 2017 & 11,91 & 33,72 & $\underline{0,001}$ & $\underline{0,010}$ & 7,30 & 4,30 & 0,63 & $\underline{0,19}$ \\
\hline & & 17,34 & 69,35 & 0,360 & $\overline{0,031}$ & $\overline{11,9}$ & $\overline{4,30}$ & $\overline{0,21}$ & $\overline{0,10}$ \\
\hline & 2018 & 74,10 & 19,76 & $\underline{0,023}$ & $\underline{0,011}$ & 15,50 & $\underline{2,85}$ & $\underline{0}$ & $\underline{0,82}$ \\
\hline & & $\overline{31,38}$ & $\overline{24,54}$ & $\overline{0,140}$ & $\overline{0,053}$ & $\overline{18,0}$ & $\overline{2,49}$ & $0, \overline{4} 7$ & $\overline{0,30}$ \\
\hline \multirow[t]{4}{*}{ Баксан } & 2017 & 14,65 & 15,94 & $\underline{0,080}$ & $\underline{0,013}$ & 7,4 & $\underline{2,25}$ & 0,42 & $\underline{0,19}$ \\
\hline & & 23,98 & 25,57 & $\overline{0,180}$ & $\overline{0,049}$ & $\overline{10,50}$ & 4,30 & $\overline{1,00}$ & $\overline{0,13}$ \\
\hline & 2018 & 17,63 & 15,86 & 0,020 & 0,005 & 9,20 & 2,18 & $\underline{0,28}$ & 0,61 \\
\hline & & 24,15 & $\overline{11,18}$ & 0,130 & $\overline{0,066}$ & $\overline{18,00}$ & 2,18 & $\overline{0,95}$ & $\overline{0,62}$ \\
\hline Чегем & 2017 & $\underline{5,63}$ & $\underline{10,23}$ & $\underline{0,002}$ & $\underline{0,016}$ & $\underline{4,30}$ & $\underline{2,56}$ & $\underline{0,16}$ & $\underline{0,29}$ \\
\hline
\end{tabular}




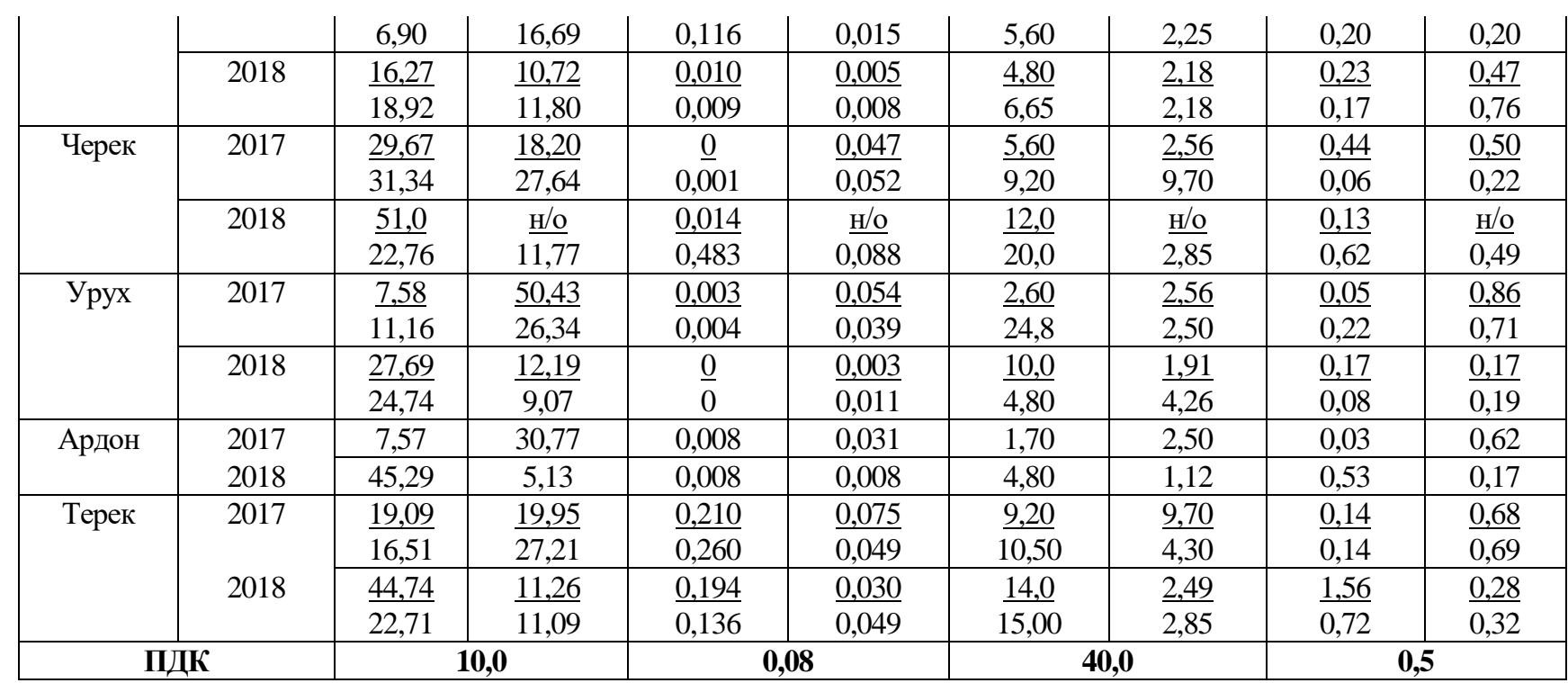

Примечания. В числителе - концентрация элемента в среднем течении, в знаменателе - в в нижнем течении; н/о - проба не отобрана.

Концентрации нитритов, превышающие предельно допустимые нормы, изменялись от 1,5 до 6 ПДК. Максимальные значения $\mathrm{NO}_{2}^{-}$составляли $0,48 \mathrm{мг} /$ дм$^{3}$ в зимних водах Черека и $0,36 \mathrm{мг} /$ дм ${ }^{3}$ в водах р. Малка. Загрязнение речных вод в межень ионами $\mathrm{NH}_{4}{ }^{+}$наблюдалось в водотоках: Малка, Баксан, Черек, Ардон, Терек (7 случаев превышения от 1 до 2 ПДК, составляя 27\% от общего количества проб), в летний паводок все реки содержали ионы аммония (11 случаев, что составляло 44\% от общего количества проб). Летние воды рек Малка, Баксан, Чегем и Черек в 2017 году были свободны от повышенных концентраций аммония, а в 2018 году зафиксировано увеличение значений $\mathrm{NH}_{4}{ }^{+}$. Впервые за многолетний период наблюдений с 2005 года зафиксировано загрязнение вод р. Ардон по $\mathrm{NH}_{4}^{+}$(1,1-1,2 ПДК). Реки отличались по степени загрязненности. Концентрация $\mathrm{NO}_{3}^{-}$за период исследований в обе фазы водного режима соответствовала требуемым нормативам и соответствовала значениям зимних и летних показателей для вод с ледниковым питанием.

Проведено 56 измерений (зима-лето) по определению марганца в ледниковых водах 7 рек. Как видно из табл. 1, в 3-х пробах воды зимней межени (Чегем, Урух и Ардон) и 2-х пробах летнего половодья (Урух и Ардон) зафиксировано, что концентрация марганца ниже ПДК, которая варьирует в пределах 5-9 мг/дм³. В остальных водах рек Мn присутствует от 1 ПДК и выше. Его высокие концентрации отмечались в р. Малка (7,4 и 6,9 ПДК) на 88 и 190 км от истока соответственно, Черек - 5,1 ПДК на 54 км, Ардон - 4,5 ПДК на 65 км и Терек - 4,5 ПДК на 151 км.

Сравнительный анализ межгодовых изменений показал, что воды рек по загрязняющим показателям отличаются. В табл. 2 представлены значения превышения ПДК в обе фазы гидрологического режима рек, где I - зимняя межень, II - летний паводок.

Таблица 2

Превышение ПДК в водах ледниковых рек зимнюю межень

и летний ппаводок, 2017-2018 годы

\begin{tabular}{|c|c|c|c|c|c|}
\hline Река & $\begin{array}{c}\text { Год } \\
\text { отбора }\end{array}$ & Место отбора & $\mathrm{Mn}$ & $\mathrm{NO}_{2}^{-}$ & $\mathrm{NH}_{4}^{+}$ \\
\hline \multirow[t]{2}{*}{ Малка } & 2017 & $\begin{array}{l}\text { Среднее течение } \\
\text { Нижнее течение }\end{array}$ & $\begin{array}{l}1,2 \text { (I), 3,4 (II) } \\
1,7 \text { (I), 6,9 (II) }\end{array}$ & 4,5 (II) & 1,3 (II) \\
\hline & 2018 & $\begin{array}{l}\text { Среднее течение } \\
\text { Нижнее течение }\end{array}$ & $\begin{array}{l}7,4 \text { (I), 2,0 (II) } \\
3,1 \text { (I), 2,5 (II) }\end{array}$ & 1,75 (I) & 1,6 (II) \\
\hline \multirow[t]{2}{*}{ Баксан } & 2017 & $\begin{array}{l}\text { Среднее течение } \\
\text { Нижнее течение }\end{array}$ & $\begin{array}{l}1,5 \text { (I), 1,6 (II) } \\
2,4 \text { (I), 2,6 (II) }\end{array}$ & $\begin{array}{l}1,0 \text { (I) } \\
2,3 \text { (I) }\end{array}$ & 2,0 (I) \\
\hline & 2018 & $\begin{array}{l}\text { Среднее течение } \\
\text { Нижнее течение }\end{array}$ & $\begin{array}{l}1,8 \text { (I), } 1,6 \text { (II) } \\
2,4 \text { (I), } 1,1 \text { (II) }\end{array}$ & 1,6 (I) & $\begin{array}{c}1,2 \text { (II) } \\
1,9 \text { (I), 1,2 (II) }\end{array}$ \\
\hline \multirow[t]{2}{*}{ Чегем } & 2017 & $\begin{array}{l}\text { Среднее течение } \\
\text { Нижнее течение }\end{array}$ & $\begin{array}{l}1,0 \text { (II) } \\
1,7 \text { (II) } \\
\end{array}$ & $1,5(\mathrm{I})$ & \\
\hline & 2018 & $\begin{array}{l}\text { Среднее течение } \\
\text { Нижнее течение }\end{array}$ & $\begin{array}{l}1,6 \text { (I), } 1,1 \text { (II) } \\
1,9 \text { (I), } 1,2 \text { (II) }\end{array}$ & & 1,5 (II) \\
\hline Черек & 2017 & Среднее течение & 3,0 (I), 1,8 (II) & & 1,0 (II) \\
\hline
\end{tabular}




\begin{tabular}{|c|c|c|c|c|c|}
\hline & & Нижнее течение & 3,1 (I), 2,8 (II) & & \\
\hline & 2018 & $\begin{array}{l}\text { Среднее течение } \\
\text { Нижнее течение }\end{array}$ & $\begin{array}{c}5,1 \text { (I) } \\
2,3(\mathrm{I}), 1,2 \text { (II) }\end{array}$ & 6,0 (I), 1,1 (II) & $1,2(\mathrm{I})$ \\
\hline \multirow[t]{2}{*}{ Уpyx } & 2017 & $\begin{array}{l}\text { Среднее течение } \\
\text { Нижнее течение }\end{array}$ & $\begin{array}{c}5,0 \text { (II) } \\
1,1 \text { (I), 2,6 (II) }\end{array}$ & & $\begin{array}{l}1,7 \text { (II) } \\
1,4 \text { (II) }\end{array}$ \\
\hline & 2018 & $\begin{array}{l}\text { Среднее течение } \\
\text { Нижнее течение }\end{array}$ & $\begin{array}{c}2,8 \text { (I), } 1,2 \text { (II) } \\
2,5 \text { (I) }\end{array}$ & & \\
\hline \multirow[t]{2}{*}{ Ардон } & 2017 & $\begin{array}{l}\text { Среднее течение } \\
\text { Нижнее течение }\end{array}$ & 3,1 (II) & & 1,2 (II) \\
\hline & 2018 & $\begin{array}{l}\text { Среднее течение } \\
\text { Нижнее течение }\end{array}$ & 4,5 (I) & & $1,1(\mathrm{I})$ \\
\hline \multirow[t]{2}{*}{ Терек } & 2017 & $\begin{array}{l}\text { Среднее течение } \\
\text { Нижнее течение }\end{array}$ & $\begin{array}{l}1,9 \text { (I), 2,0 (II) } \\
1,7 \text { (I), 2,7 (II) }\end{array}$ & $\begin{array}{l}2,6 \text { (I) } \\
3,3 \text { (I) }\end{array}$ & $\begin{array}{l}1,4 \text { (II) } \\
1,4 \text { (II) }\end{array}$ \\
\hline & 2018 & $\begin{array}{l}\text { Среднее течение } \\
\text { Нижнее течение }\end{array}$ & $\begin{array}{l}4,5 \text { (I), 1,1 (II) } \\
2,3 \text { (I), } 1,1 \text { (II) }\end{array}$ & $\begin{array}{l}2,4(\mathrm{I}) \\
1,7 \text { (I) }\end{array}$ & $\begin{array}{l}3,1(\mathrm{I}) \\
1,4(\mathrm{I})\end{array}$ \\
\hline
\end{tabular}

Установлено, что основными загрязняющими компонентами речных вод являются $\mathrm{NO}_{2}^{-}, \mathrm{NH}_{4}{ }^{+}$и $\mathrm{Mn}$. Выявлены высокие концентрации, изменяющие соотношение компонентов в сторону накопления. По экологическим классам качества вод реки в 2017-2018 гг. загрязнены нитритами, аммонием и квалифицируются как «грязные» и «сильно загрязненные». Отмечается повышенный уровень загрязнения марганцем в обе фазы гидрологического режима рек. Концентрация марганца в поверхностных водах подвержена сезонным колебаниям.

\section{Выводы}

Прослежена динамика распределения изменения концентраций загрязняющих веществ по годам. Выявлено, что в 2017 году отмечалась тенденция к уменьшению концентраций нитратов, нитритов и аммония в водах ледниковых рек Черек, Урух и Ардон, воды рек Малка, Баксан, Чегем и Черек летнего отбора по экологическим классам относятся к «чистым». В 2018 году только река Урух в обе фазы гидрологического режима содержит соединения азота ниже ПДК. Проведена оценка фактического состава и качества ледниковых вод по предельно допустимым концентрациям, что связано с ее значением для использования в рыболовстве, туризме, поливе сельскохозяйственных угодий, обеспечения населения питьевой водой и промышленного производства.

При миграции загрязнители, проникая в речные воды, ухудшают качество и экологическую безопасность. Продолжение исследования вод по содержанию неорганических соединений азота необходимо, так как это обязательные компоненты природных вод, являющиеся важными экологическими показателями. В связи с изменением климата, увеличением выпадения ливневых осадков, смывающих с полей загрязняющие вещества в русла рек, интенсивным таянием ледников и снежников, увеличивающих эрозию почв, оказывающих влияние на химический состав поверхностных вод и экологическое состояние бассейнов представленных рек, необходимо продолжать наблюдения за составом и качеством.

\section{Библиографический список}

1. Аджиева А.А., Кондратьева Н.В. Изменение климата и гидрометеорологические явления в горных районах Кавказа // Устойчивое развитие горных территорий. 2009. № 1. С. 68-72.

2. Разумов В.В., Курданов Х.Х., Разумова А.Г., Крохмаль А.Г., Батырбекова Л.М. Экосистемы гор центрального Кавказа и здоровье человека. - М., Илекса, 2003. 448 с.

3. Чередник Е.А., Жинжакова Л.З., Отарова А.С. Многолетние данные состава основных водных артерий и малых рек Центрального Кавказа по физическим и химическим параметрам. Свидетельство о государственной регистрации базы данных RUS 2019620642 18.04.2019.

4. Zhinzhakova L. Z. Violation of Environmental Standards for Inorganic Nitrogen Compounds in Glacial Rivers of the Central Caucasus in 2017-2019 // Russian Journal of General Chemistry. 2020. Vol. 90. No. 13, pp. 2593-2598. DOI: $10.1134 / \mathrm{S} 1070363220130101$

5. Воробьева Т.И., Гущина Л.П., Чередник Е.А., Жинжакова Л.З. Вынос токсичных ингредиентов в воды Терека основными реками Центрального Кавказа // В сб.: Моделирование устойчивого регионального развития. Материалы III Международной конференции. - Нальчик, 2009. С.172-177.

6. Воробьева Т.И., Гущина Л.П., Чередник Е.А., Реутова Т.В., Жинжакова Л.З. Экологическое состояние водных артерий Центрального Кавказа // Известия Кабардино-Балкарского научного центра РАН, 2010. № 1 (33). С. 151-157.

7. Воробьева Т.И., Гущина Л.П., Жинжакова Л.З., Реутова Т.В., Чередник Е.А., Машуков Х.Х. Динамика уровней концентраций тяжелых металлов и неорганических форм азота в водах рек Центрального Кавказа // В 
сб.: Современные проблемы гидрохимии и формирования качества вод. Материалы научной конференции (с международным участием). - Ростов-на-Дону. 2010. С.93-96.

8. Реутова Т.В., Воробьева Т.И., Гущина Л.П., Жинжакова Л.З., Чередник Е.А. Оценка уровня загрязнения рек Центрального Кавказа по результатам 10-летнего мониторинга // В сб.: Бассейн реки Терек: Проблемы регулирования, восстановления и реабилитации водных объектов / Труды Всероссийской научно-практической конференции. Западно-Каспийское бассейновое водное управление. Открытое акционерное общество «Севкавгипроводхоз»; отв. C. 232-237.

9. Воробьева Т.И., Жинжакова Л.3., Чередник Е.А., Отарова А.С. Оценка фонового уровня содержания микропримесей в речных водах на территории Центрального Кавказа // В кн.: Геолого-геофизические исследования глубинного строения Кавказа: Геология и геофизика Кавказа: современные вызовы и методы исследований. Коллективная монография. - Владикавказ. 2017. С. 535-542.

10. РД 52.24.353-2012. Рекомендации. Отбор проб поверхностных вод суши и очищенных сточных вод. M., $27 \mathrm{c}$.

11. МВИ (ФР.1.31.2005.01724). Методика выполнения измерений массовой концентрации анионов методом ионной хроматографии. - М., $30 \mathrm{c}$.

12. МВИ (ФР.1.31.2005.01738). Методика выполнения измерений массовой концентрации катионов методом ионной хроматографии. - М., 26 с.

13. РД 52.24.367-2010. Руководящий документ. Массовая концентрация нитратов в водах. Методика выполнения измерений потенциометрическим методом с ИСЭ. 2010. $21 \mathrm{c.}$

14. ПНД Ф 14.1:2.253-09. Методика выполнения измерений массовых концентраций $\mathrm{Al}, \mathrm{Ba}, \mathrm{Be}, \mathrm{V}, \mathrm{Fe}, \mathrm{Cd}$, $\mathrm{Co}, \mathrm{Li}, \mathrm{Mn}, \mathrm{Cu}, \mathrm{Mo}, \mathrm{As}, \mathrm{Ni}, \mathrm{Sn}, \mathrm{Pb}, \mathrm{Se}, \mathrm{Sr}, \mathrm{Ti}, \mathrm{Cr}, \mathrm{Zn}$ в природных и сточных водах методом атомноабсорбционной спектроскопии с использованием атомно-абсорбционного спектрометра с электротермической атомизацией «МГА-915». - М., 2013. 36 с.

15. Войткевич Г.В., Кокин А.В., Мирошников А.Е., Прохоров В.Г. Справочник по геохимии. - М.: Недра, 1990. $480 \mathrm{c}$.

16. Перечень нормативов качества воды водных объектов рыбохозяйственного значения, в том числе нормативов предельно допустимых концентраций вредных веществ в водах водных объектов рыбохозяйственного значения [Текст] / Приказ Росрыболовства от 13 декабря 2016 г. № 552 «Об утверждении нормативов качества воды водных объектов рыбохозяйственного значения, в том числе нормативов предельнодопустимых концентраций вредных веществ в водах водных объектов рыбохозяйственного значения (с изменениями на 12 октября 2018 года).

17. Нежиховский Р.А. Гидролого-экологические основы водного хозяйства. - Л.: Гидрометеоиздат, 1990. 229 c.

18. СанПиН 2.1.4.1175-02. Гигиенические требования к качеству воды нецентрализованного водоснабжения. Санитарная охрана источников. М., 2002. 20 с.

19. ГН 2.1.5.1315-03. ПДК химических веществ в воде водных объектов хозяйственно-питьевого и культурно-бытового назначения. Нормативы распространяются на воду подземных источников и поверхностных водотоков, используемых для централизованного и нецентрализованного водоснабжения населения. - М., 2003. 84 c.

20. Никаноров А.М. Справочник по гидрохимии. - Л.: Гидрометеоиздат, 1989. 392 с.

\section{References}

1. Adzhieva A.A., Kondratyeva N.V. Climate change and hydrometeorological phenomena in the mountainous regions of the Caucasus // Ustoychivoye razvitiye gornykh territoriy. 2009. No. 1. pp. 68-72. (In Russian).

2. Razumov V.V., Kurdanov Kh.Kh., Razumova A.G., Krokhmal A.G., Batyrbekova L.M. Ecosystems of the mountains of the Central Caucasus and human health. - M., Ileksa, 2003.448 p. (In Russian).

3. Cherednik E.A., Zhinzhakova L.Z., Otarova A.S. Long-term data on the composition of the main waterways and small rivers of the Central Caucasus in terms of physical and chemical parameters. Svidetel'stvo o gosudarstvennoy registratsii bazy dannykh RUS 2019620642 04/18/2019. (In Russian).

4. Zhinzhakova L. Z. Violation of Environmental Standards for Inorganic Nitrogen

Compounds in Glacial Rivers of the Central Caucasus in 2017-2019 // Russian Journal of General Chemistry. 2020. Vol. 90. No. 13, pp. 2593-2598. DOI: 10.1134 / S1070363220130101

5. Vorobieva T.I., Gushchina L.P., Cherednik E.A., Zhinzhakova L.Z. Removal of toxic ingredients into the waters of the Terek by the main rivers of the Central Caucasus // V sb.: Modelirovaniye ustoychivogo regional'nogo razvitiya. Materialy III Mezhdunarodnoy konferentsii. - Nalchik, 2009.S. 172-177. (In Russian).

6. Vorobieva T.I., Gushchina L.P., Cherednik E.A., Reutova T.V., Zhinzhakova L.Z. The ecological state of the waterways of the Central Caucasus // Izvestiya Kabardino-Balkarskogo nauchnogo tsentra RAN, 2010. No. 1 (33). pp. 151-157. (In Russian). 
7. Vorobieva T.I., Gushchina L.P., Zhinzhakova L.Z., Reutova T.V., Cherednik E.A., Mashukov Kh.Kh. Dynamics of concentration levels of heavy metals and inorganic forms of nitrogen in the waters of the rivers of the Central Caucasus. V sb.: Sovremennyye problemy gidrokhimii i formirovaniya kachestva vod. Materialy nauchnoy konferentsii (s mezhdunarodnym uchastiyem). - Rostov-na-Donu. 2010. pp. 93-96. (In Russian).

8. Reutova T.V., Vorobieva T.I., Gushchina L.P., Zhinzhakova L.Z., Cherednik E.A. Assessment of the level of pollution of the rivers of the Central Caucasus based on the results of 10-year monitoring. V sb.: Basseyn reki Terek: Problemy regulirovaniya, vosstanovleniya i reabilitatsii vodnykh ob"yektov / Trudy Vserossiyskoy nauchnoprakticheskoy konferentsii. Zapadno-Kaspiyskoye basseynovoye vodnoye upravleniye. Otkrytoye aktsionernoye obshchestvo «Sevkavgiprovodkhoz»; otv. redaktor E.V. Zaporozhchenko. 2015. pp. 232-237. (In Russian).

9. Vorobieva T.I., Zhinzhakova L.Z., Cherednik E.A., Otarova A.S. Assessment of the background level of trace impurities in river waters in the Central Caucasus // V kn.: Geologo-geofizicheskiye issledovaniya glubinnogo stroyeniya Kavkaza: Geologiya i geofizika Kavkaza: sovremennyye vyzovy i metody issledovaniy. Kollektivnaya monografiya. - Vladikavkaz. 2017. pp. 535-542. (In Russian).

10. RD 52.24.353-2012. Rekomendatsii. Otbor prob poverkhnostnykh vod sushi i ochishchennykh stochnykh vod. M., 27 p. (In Russian).

11. MVI (FR.1.31.2005.01724). Metodika vypolneniya izmereniy massovoy kontsentratsii anionov metodom ionnoy khromatografii. - M., 30 p. (In Russian).

12. MVI (FR.1.31.2005.01738). Methods for measuring the mass concentration of cations by ion chromatography. M., 26 p. (In Russian).

13. RD 52.24.367-2010. Rukovodyashchiy dokument. Massovaya kontsentratsiya nitratov Metodika vypolneniya izmereniy massovoy kontsentratsii anionov metodom ionnoy khromatografii v vodakh. Metodika vypolneniya izmereniy potentsiometricheskim metodom s ISE. 2010. 21 p. (In Russian).

14. PND F 14.1: 2.253-09. Metodika vypolneniya izmereniy massovykh kontsentratsiy Al, Ba, Be, V, Fe, Cd, Co, $\mathrm{Li}, \mathrm{Mn}, \mathrm{Cu}, \mathrm{Mo}, \mathrm{As}, \mathrm{Ni}, \mathrm{Sn}, \mathrm{Pb}, \mathrm{Se}, \mathrm{Sr}, \mathrm{Ti}, \mathrm{Cr}, \mathrm{Zn}$ v prirodnykh i stochnykh vodakh metodom atomno-absorbtsionnoy spektroskopii s ispol'zovaniyem atomno-absorbtsionnogo spektrometra s elektrotermicheskoy atomizatsiyey "MGA915". - M., 2013.36 p. (In Russian).

15. Voitkevich G.V., Kokin A.V., Miroshnikov A.E., Prokhorov V.G. Handbook of geochemistry. - M.: Nedra, 1990.480 p. (In Russian).

16. Perechen' normativov kachestva vody vodnykh ob"yektov rybokhozyaystvennogo znacheniya, $v$ tom chisle normativov predel'no dopustimykh kontsentratsiy vrednykh veshchestv v vodakh vodnykh ob"yektov rybokhozyaystvennogo znacheniya [Tekst] / Prikaz Rosrybolovstva ot 13 dekabrya 2016 g. № 552 «Ob utverzhdenii normativov kachestva vody vodnykh ob"yektov rybokhozyaystvennogo znacheniya, $\mathrm{v}$ tom chisle normativov predel'nodopustimykh kontsentratsiy vrednykh veshchestv v vodakh vodnykh ob"yektov rybokhozyaystvennogo znacheniya (s izmeneniyami na 12 oktyabrya 2018 goda). (In Russian).

17. Nezhikhovsky R.A. Hydrological and ecological foundations of water management. - L.: Gidrometeoizdat, 1990. 229 p. (In Russian).

18. SanPiN 2.1.4.1175-02. Hygienic Requirements for Water Quality in Decentralized Water Supply. Sanitary protection of sources. M., 2002.20 p. (In Russian).

19. GN 2.1.5.1315-03. PDK khimicheskikh veshchestv v vode vodnykh ob"yektov khozyaystvenno-pit'yevogo i kul'turno-bytovogo naznacheniya. Normativy rasprostranyayutsya na vodu podzemnykh istochnikov i poverkhnostnykh vodotokov, ispol'zuyemykh dlya tsentralizovannogo i netsentralizovannogo vodosnabzheniya naseleniya. - M., 2003.84 p. (In Russian).

20. Nikanorov A.M. Handbook of Hydrochemistry. - L.: Gidrometeoizdat, 1989. 392 p. (In Russian). 